\title{
National Institute on Aging
}

National Cancer Institute

\section{Source}

National Cancer Institute. National Institute on Aging. NCI Thesaurus. Code C82604.

An institute within the National Institutes of Health that leads a broad scientific effort to understand the nature of aging and to extend the healthy, active years of life. 